Max-Planck-Institut für demografische Forschung

Max Planck Institute for Demographic Research

Konrad-Zuse-Strasse 1 - D-18057 Rostock · GERMANY

Tel +49 (0) 3812081 - 0; Fax +49 (0) 3812081 - 202;

http://www.demogr.mpg.de

MPIDR WORKING PAPER WP 2006-029

AUGUST 2006

\title{
Employment Experience and First Birth in Great Britain
}

Cordula Zabel (zabel@ demogr.mpg.de)

This working paper has been approved for release by: Gerda Ruth Neyer (neyer@ demogr.mpg.de) Deputy Head of the Laboratory of Contemporary European Fertility and Family Dynamics.

(C) Copyright is held by the authors.

Working papers of the Max Planck Institute for Demographic Research receive only limited review. Views or opinions expressed in working papers are attributable to the authors and do not necessarily reflect those of the Institute. 


\title{
Employment Experience and First Birth in Great Britain
}

Cordula Zabel

\begin{abstract}
This article examines the effect of employment experience on first birth risks in Great Britain. The data used is from the British Household Panel Survey (BHPS). A positive effect of employment experience on first birth risks is found, in accordance with predictions from economic models of fertility timing. This effect did not differ greatly between educational groups, in contrast to what was expected. Positive effects were found for all educational groups. An especially strong increase in first birth risks was found across the first year of employment spells.
\end{abstract}




\section{Introduction}

In this study, the impact of employment experience on transitions to first birth is investigated using data from the British Household Panel Survey (BHPS). Economic models of fertility timing usually predict a positive effect of later vs. earlier births within the career on life-time earnings, whether assuming wage depreciation during absence from employment (Hotz et al. 1997), or more rapid human capital accumulation at the beginning of the career (Gustafsson 2001). This is supported by qualitative studies which have found that women frequently wait until they have advanced to a certain level in their career before deciding to have children (Ranson 1998). Because early phases of career building are often more crucial for women with higher levels of qualification, the advantage of postponing first birth should be greater for them. The main hypothesis investigated here is therefore that employment experience, while having a positive effect on first birth risks for all women, will have a stronger effect for women with higher levels of education.

Despite low levels of public childcare for young children in Great Britain (Randall 1996; Evers et al. 2005; Department for Education and Skills 2001), employment interruptions around childbirth are relatively short in international comparison (Gustafsson et al. 1996). Mothers usually need to find a strategy how to combine childcare and employment despite a relatively unsupportive institutional framework (Ward et al. 1996; Woodland et al. 2004). In this context, work experience may be especially important for fertility decisions, in order to achieve employment security before having children. Theories on the importance of work experience for fertility decisions will be reviewed in more detail in the following section. This is succeeded by a review of previous empirical studies. Next, the applied data and methods are briefly discussed. After that, the results of the empirical analyses are presented. Finally, the main findings are summarized.

\section{Theoretical considerations on the relationship between employment experience and first birth timing}

The impact of work experience on fertility is a special issue within the wider discussion of the relationship between women's employment and fertility. Investigations of 
the relationship between women's employment and fertility are commonly centered around theories of the opportunity costs of childbearing. On a very general level, opportunity cost theories hold that women's income has a negative effect on fertility, because forgone earnings during time spent out of the labor market caring for children are higher for women with a higher earning potential (Leibenstein 1957; Schultz 1969). Early empirical studies have found evidence of a negative effect of women's income on fertility (Mincer 1963; Cain and Weininger 1973). More recently, as women more strongly assume the roles of providers for their families, some studies have by contrast found a positive effect of women's income on fertility. This is especially the case for Scandinavian countries (Andersson 2000; Vikat 2004), where the compatibility of work and childrearing is generally quite high. For other countries such as Germany and Great Britain, the direction of the effect is not so clear (Kreyenfeld 2005; Ermisch 1989).

Altogether, it is thus not so evident whether higher earnings generally have a negative effect on fertility, as purported by theories of opportunity costs. Economic theories of fertility timing also assume that women seek to avoid opportunity costs of childbearing. This does not however imply that present earnings need necessarily have a negative effect on fertility. The focus in economic theories of fertility timing is on aggregated life-time earnings instead of present earnings.

In the following, after reviewing economic theories of fertility timing, the importance of work experience for gaining a secure employment position before having children will also be discussed.

\subsection{Life-time earnings and optimal age at first birth}

In an evaluation of the literature on life-cycle models of fertility, Hotz et al. (1997) state that in models assuming skill depreciation during employment interruptions, later birth timing has a positive effect on a mother's life-time earnings, as long as she has some initial earning power. If she has no initial earning power at the start of the fertility planning period, life-time earnings will be higher the earlier the birth is timed.

This can also be shown using a simple model of linear skill appreciation and depreciation, as illustrated in figure 1 . Here, the dotted line represents the wage function that would apply if there were no employment interruption. The initial level of 
wages is given by $a$. The length of employment interruption around childbirth is represented by the duration $d_{l}$. The level of skills and thus attainable wages depreciates during absence. Therefore, wages after the employment interruption are lower than before. The shaded area gives the life-time earnings.

Figure 1: linear model of skill appreciation and depreciation

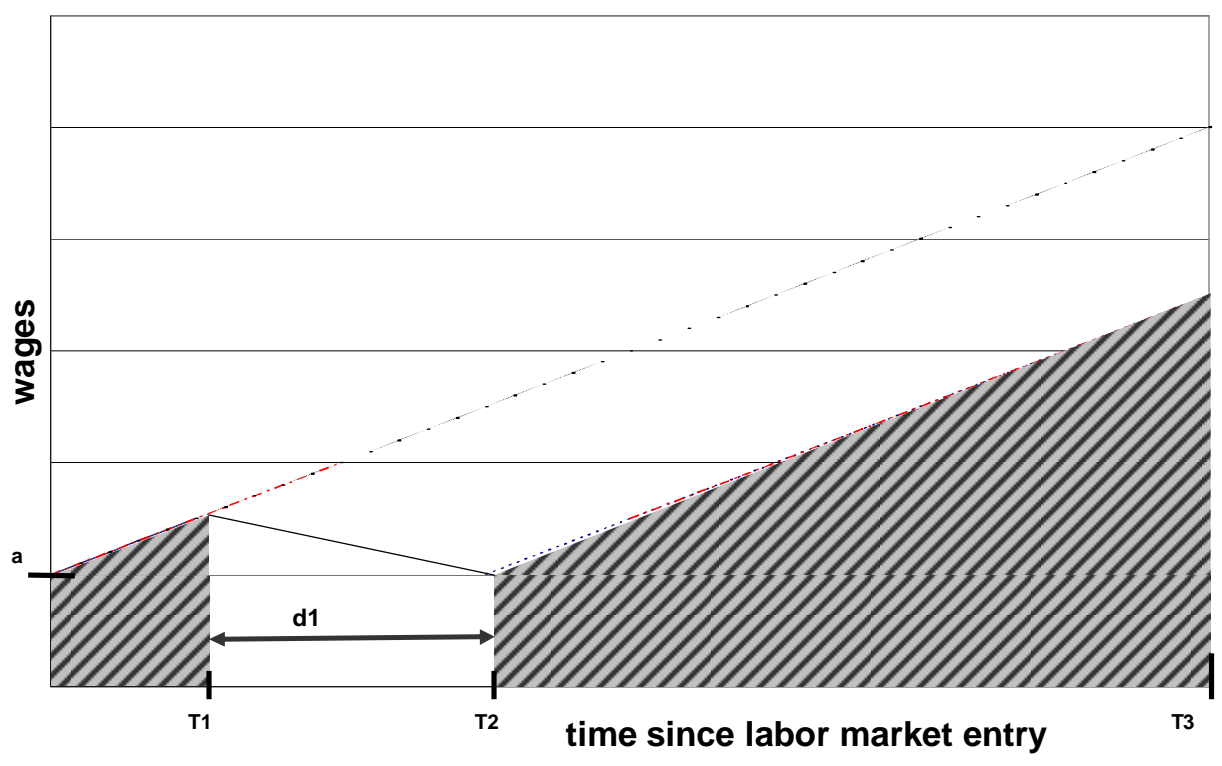

In a standard case such as that illustrated in figure 1, skills do not depreciate completely during absence. As one can see in figure 1, wages do not decrease all the way to zero during absence. As long as this is the case, later birth timing leads to higher life-time earnings. This is shown in the appendix.

Skills can however depreciate completely during absence if the duration of leave is very long, the initial level of skills is very low, or the rate of depreciation is very high. In any of these cases, the effect of postponing birth on life-time earnings can be partially negative. Variation in the values of the parameters duration of leave, initial earnings, and rate of skill depreciation can alter the effect of birth timing on life-time earnings in other ways too. Figure 2 below shows the sensitivity of the effect of birth timing on life-time earnings to the duration of leave, skill depreciation, and initial level of skills in a series of simulations assuming different values for these parameters. The first curve from the top in figure 2 (labeled 'standard') gives the effect of birth timing on life-time earnings assuming a standard set of parameters that do not 
allow complete skill depreciation during absence. As one can see, life-time earnings increase linearly the later the birth is timed. The effect of later birth timing becomes stronger if either the rate of skill depreciation is higher or the duration of leave is longer, as can be seen by comparing the first two curves. Extreme values for each of the parameters duration of leave, initial earnings, and rate of skill depreciation are then assumed in turn in figure 2. These values allow complete skill depreciation for early births, when the acquired level of skills is not yet high. In each of the three cases shown here, the effect of postponing birth is therefore at first negative so long as skills depreciate completely during absence. The effect of postponing birth then becomes positive as soon as the acquired level of skills is high enough not to depreciate completely. The corresponding formulas are given in the appendix.

For women with higher levels of qualifications, skill depreciation during absence is usually assumed to be greater. As already mentioned, if the rate of skill depreciation is set to be higher, the positive effect of birth timing on life-time earnings is stronger than for the standard case, as can be seen in figure 2 by comparing the steeper curve labeled 'quick depreciation or long leave' to the standard curve. If however the rate of skill depreciation is extremely high (as assumed next for the curve labeled 'extremely quick depreciation'), so that low levels of skills early on in the career can depreciate completely during absence, the effect of postponing birth is at first negative. 


\section{Figure 2: Sensitivity of the effect of birth timing on life-time earnings} to wage and leave parameters ${ }^{1}$

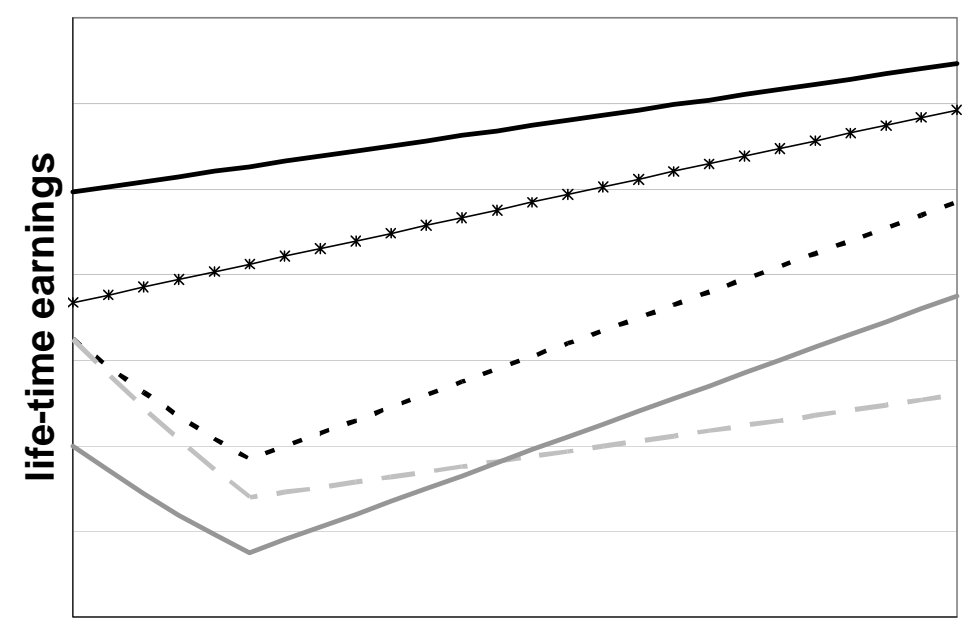

time of birth

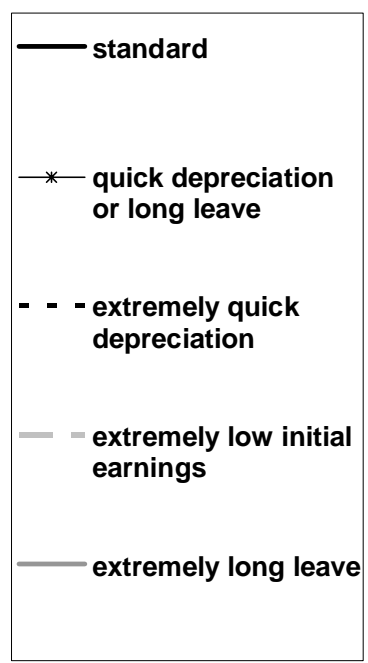

Women with low levels of formal qualifications are usually assumed to have a low initial earning potential. So for the next curve in figure 2, the initial earning potential was set to be very low. This produces an effect of birth timing that is at first negative. Across the segment where the effect is positive, it however remains unaffected and is of the same strength as in the standard case. Thus, for women with very low initial skill levels, very early births can be advantageous in terms of life-time earnings.

Women with lower levels of qualifications have also been found to take longer durations of leave (Gustafsson et al. 1996; Joshi 2002; Bender et al. 2003). Again, comparing the first two curves, one can see that this strengthens the positive effect of later birth timing. The last curve in figure 2 shows the shape of the timing effect given very long durations of leave. The timing effect here is very similar to the effect produced when assuming extremely high rates of skill depreciation (described above). If the duration of leave is extremely long (as assumed here) the effect of postponing birth can at first be negative, followed by a stronger positive effect than was the case for the standard model.

To summarize, if one does not assume extreme values for the length of employment interruption, rate of skill depreciation, or initial level of earnings, later birth

\footnotetext{
${ }^{1}$ A graph that similarly shows an initial negative effect of birth timing on life-time earnings followed by a positive effect can be found in Happel, Hill and Low (1984).
} 
timing increases life-time earnings. Higher rates of skill depreciation or longer durations of leave strengthen this positive effect. Beyond a certain level though, they also lead to an initial negative effect of postponing births. Low starting levels of earnings also lead to an initial negative effect, but without strengthening the eventual positive effect that sets in after some employment experience has been gathered. The conclusion for the impact of formal qualifications on the timing effect is unclear. Women with higher levels of qualifications are usually assumed to have higher rates of skill depreciation during absence, but shorter durations of leave. The first factor points to a stronger positive effect of postponing births for women with higher levels of qualification (if the rate of depreciation is not so extremely high as to produce an initial negative effect). The short leave durations by contrast point to a weaker effect. So, the model of linear skill appreciation and depreciation does not give any clear implications as to the impact of education on the relationship between fertility timing and life-time earnings. A positive effect of postponing birth on life-time earnings is generally predicted for all women, as long as leave and wage parameters do not have extreme values. However, it is not so clear whether this is more or less so for those with higher than for those with lower levels of qualification.

In the model of linear skill appreciation described above, timing can only have an effect on life-time earnings if skills are assumed to depreciate during absence from the labor market. Without skill depreciation, there is no timing effect. Gustafsson (2001) proposes a different model of skill appreciation across the life-course, where at first wages increase strongly with age, but then continue to rise ever more slowly as people grow older. Given this type of an assumption about the nature of skill appreciation by age, timing becomes relevant even if there is no skill depreciation during times of absence from the labor market. In the appendix, this is shown assuming that wages increase as a multiple of a root of age. Income losses are then smaller for late than early births, and the more so the longer the duration of leave and the greater a factor determining the rate of skill appreciation.

Again, the impact of level of qualification on the timing effect is unclear. Skill appreciation may be stronger for women with higher levels of qualification, but these women also tend to take shorter leaves around childbirth. So, like in the linear model, the prediction from this model is that later birth timing generally has a positive effect on life-time earnings, but it is not so clear if this is more or less so for women with higher qualifications. 
This positive effect of later timing is illustrated in figure 3. It is shown here that while the immediate income loss is greater for later births than earlier births, the long-term effect for future earnings decreases disproportionately for later births, causing a positive effect of later birth timing.

Figure 3: Effect of timing of first birth on life-time earnings with declining wage growth

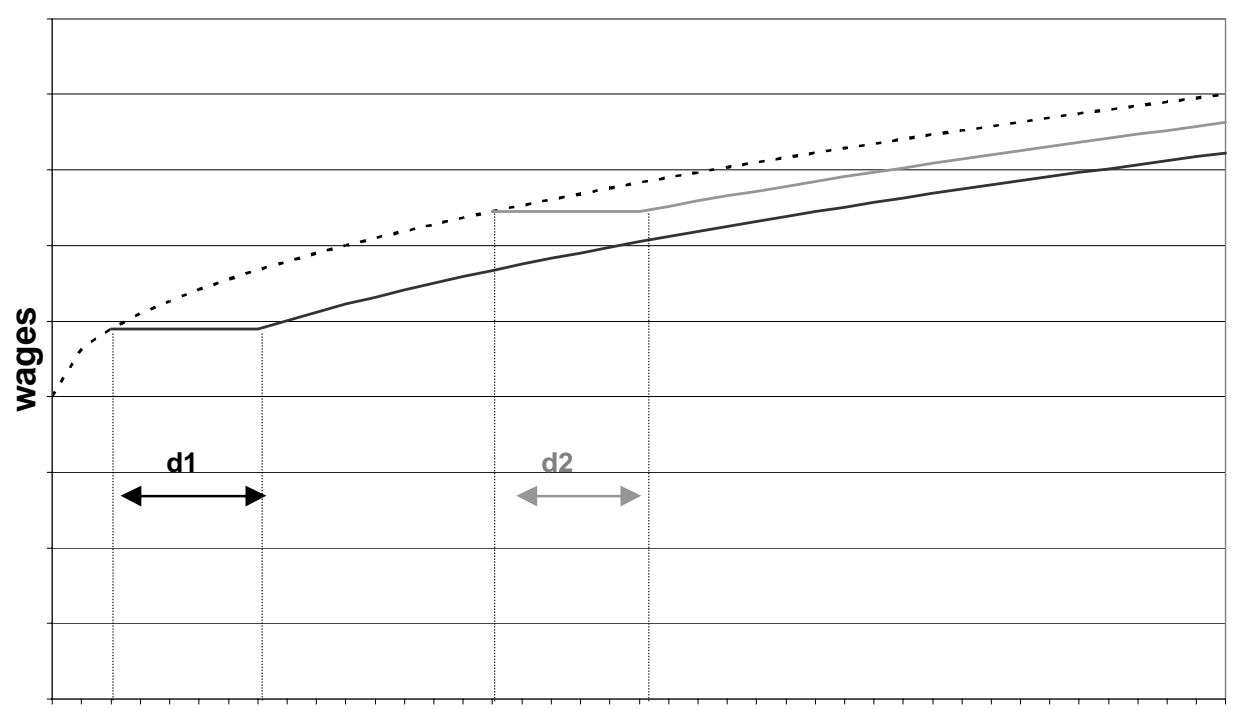

time since labor market entry

The age dependency of rate of wage growth proposed by Gustafsson (2001) does seem plausible, if one assumes that most promotions take place nearer to the beginning of peoples' careers. Also, as Gustafsson (2001) points out, employers tend to recruit younger employees for positions that require large amounts of training. One problem with this model might be, though, that wage growth may not be quite as strictly age-dependent as proposed by Gustafsson (2001). In Gustafsson's (2001) model, wage growth at labor market reentry is given by one's age (or time since initial labor market entry). However, one might assume that a person reentering the labor market has a different rate of wage growth at this time point than someone who had been employed all the time. At least partly, wage growth may also depend on employment experience and tenure as well.

To summarize, if one either assumes that skills depreciate with time outside the labor market or that earnings profiles are steeper at younger ages, then the conclusion for the effect of birth timing is generally that losses to life-time earnings are 
smaller the longer the birth is postponed. If skills are taken to depreciate during absence, extreme rates of depreciation, lengths of leave, or initial level of earnings can lead to a negative effect of postponing births while acquired skills are still low.

\subsection{Employment security and first birth}

Implications for life-time earnings of patterns of skill appreciation and depreciation may not be the only reason to postpone births. Instead, it has often been argued that laying the foundations for ones employment career is an important prerequisite for fertility decision-making (Taniguchi 1999; Lappegård and Rønsen 2004; Brewster and Rindfuss 2000). It is however difficult to find direct evidence of this type of a connection between employment experience and first birth timing from quantitative studies. Support for the idea that early career establishment is important for fertility decisionmaking is provided by a qualitative study by Ranson (1998) of female university graduates in Edmonton, Canada. The respondents in this study regularly named the achievement of job security as an important consideration that had influenced their decision of when to become mothers. Respondents who already had children named the achievement of professional status, reaching a certain rank, or a permanent contract and the entitlement to maternity leave, as preconditions for deciding to become mothers. Some of the respondents who had not yet had children by the age of 30 reported that they had postponed motherhood in part because of difficulties establishing their careers. Some had changed occupations, and were therefore several years behind in gaining work experience. Teachers who had not been able to achieve tenure were also postponing having a first child (Ranson 1998).

The results from this qualitative study indicate that it may not only be rates of skill appreciation or depreciation that determine the optimal timing of births. The assumption in economic theories of fertility timing seems to be that skill levels translate directly into job options. Given a framework of welfare state and labor market institutions, though, factors apart from the amount of skill depreciation during absence may be important for birth timing decisions as well. The ability to retain one's job after having a child may have little to do with ones level of skills, and more with legislation, firm policies, or customary practices. These, too, may be responsive to the length of employment tenure. 
All of the theoretical considerations reviewed in this section implicitly assume that women interrupt their employment for some period of time around childbirth. This still seems to apply to the majority of women in Great Britain, although employment interruptions are relatively short in international comparison and a small proportion of women return to employment almost immediately after having their child. Even without employment interruptions, women may still have reason to take their employment experience into account in deciding when to have a child. They may want to be certain of having a secure position in order to better be able to support their family. They may also fear that discriminating treatment could prevent them from achieving a secure position.

\subsection{Hypotheses}

Judging from economic models of life-cycle fertility, gathering more employment experience before having a first child almost always leads to higher life-time earnings. Exceptions are extremely high rates of wage depreciation, long durations of leave, or low initial earnings, as soon as they lead to total depreciation of skills during absence. If we assume that these types of extreme cases are rare, the hypothesis follows that employment experience generally has a positive effect on transitions to first birth. No clear predictions as to differences in this effect by education ensue from economic models of fertility timing. However, if one assumes that life-time employment outcomes are not only determined by lengths of leave or rates of skill depreciation during absence, but also by the level of employment security achieved before birth, there may be reasons to expect differences in the effect of employment experience on first birth transitions by level of education after all. If women with higher levels of education take longer to establish their careers, this might lead to later birth timing. Therefore a second hypothesis is that the positive effect of employment experience is stronger for women with higher levels of education. 


\section{Research on the relationship between work experience, fertility, and employment outcomes}

\subsection{Empirical research on the effect of timing of childbearing on wages}

Blackburn, Bloom, and Neumark (1993) look at the effect of fertility timing on wages of women aged 28-38 in 1982 in the United States and find that women who have their first child later earn higher wages. They find that most but not all of this effect can be explained by differences in education, experience and tenure. They also estimate models accounting for the possible impact of early wages on fertility timing. This does not however greatly alter the results. The authors conclude that the positive association between later childbearing and wages can be mainly attributed to later childbearers' greater human capital investments. This is in accordance with their theoretical life-cycle model which demonstrates that women who choose to have children later also choose to invest in their human capital. Since both the birth timing and the human capital investment choice are seen to have been made simultaneously at the beginning of the career, no room is left in this model for unplanned impacts of fertility timing on wages.

A way to gain a more detailed picture of the impact of fertility timing on wages may be to differentiate between employment experience gained before and after birth. In a study of women born between 1944 and 1954 in the United States, Taniguchi (1999) finds that women aged 20-27 at first birth experience a wage penalty compared to childless women even when controlling for work experience, education, and demographic variables. With these control variables, women older than 28 at first birth however experience no significant wage penalty. Before controlling for unobserved heterogeneity, work experience after birth had a stronger effect on wages than work experience before birth; this was reversed when controlling for unobserved heterogeneity. The author speculates that this may be due to unobserved characteristics associated with higher earnings potentials of those who return to work quickly. It would then not as much be the work experience gathered after birth, but the impact of these unobserved characteristics that leads to higher wages.

In a simulation by Joshi (1990) of women's forgone earnings due to motherhood, based on an analysis of a 1980 cross-section of British women, the effect of 
timing of childbearing on the wage penalty for motherhood is also tested, and found to be very small.

Thus the empirical evidence for an effect of fertility timing on wages is mixed. Especially, it does not seem that there are many studies focusing specifically on this question. The finding by Taniguchi (1999) that work experience before birth is important for the level of wages may support the idea that establishing employment security by greater work experience is important for mothers' employment outcomes.

\subsection{The opposite direction: Empirical research on the effect of labor market ex- perience on the timing of childbearing}

If women have reason to believe that the timing of childbearing affects their future wages or employment prospects, this may influence their decisions about when to have a first child. Various studies have found an effect of work experience or time since leaving education on the transition to first birth. For example, Kravdal (1994) finds that first birth risks increase during the first 4 years of work experience in Norway. Vikat (2004) finds for Finland that first birth risks rise with the amount of time spent in employment or unemployment (as opposed to non-employment) during the last year.

Some studies have also examined whether the effect of time since leaving education varies with educational attainment. Kreyenfeld (2004) compares women with different levels of education in East and West Germany before unification. She finds that in East Germany, first birth risks are highest just after exiting the education system for all levels of educational attainment and decrease thereafter. By contrast, in West Germany, first birth risks are lowest just after leaving the education system and increase during 2-6 years after leaving education. The dependence of first birth risks on time since leaving education differs more by educational level in West than in East Germany, with lower risks at the beginning and stronger increases later on for higher levels of educational attainment. Kantorová (2004) finds for the Czech Republic that in the period between 1979 and 1989, first birth risks increased very strongly immediately after the end of education, especially for those with the highest level of educational attainment. By contrast, in the period between 1990 and 1997, first birth risks 
increased much more slowly after the end of education, particularly among those with the highest level of education.

Some analyses have also looked into differences in fertility timing between occupations. Happel, Hill, and Low (1984), for example, found for American women born between 1944 and 1954 that those in high-skilled occupations postponed first births longer than those in low-skilled occupations. Cigno and Ermisch (1989), using a survey of British women aged 16-59 in 1980, compare fertility rates of women with different amounts of work experience before marriage, different levels of education, and different occupations, while not differentiating by birth order. They find that women with more work experience before marriage have lower overall fertility rates. They also find that women in clerical occupations have children later in marriage than women in semi-skilled manual occupations, and take this to support the hypothesis that women in clerical occupations can expect higher returns to experience and thus delay childbearing. Interestingly, they also find that women with higher levels of education have higher birth rates. However, the authors argue that this may be due to misspecification of their model, which may not include enough of the husband's characteristics.

For many of the countries named above, then, first birth risks are found to increase with time in the labor market. This was found to be the case in Norway, Finland, West Germany, and in the Czech Republik after 1989. Only in East Germany and the Czech Republic before 1990 are first birth risks highest right after ending education. Perhaps this was because job security was so high and childcare was so well provided for that women did not have to fear negative impacts of early childbearing on their labor market prospects (Kantorová 2004; Kreyenfeld 2004). For Great Britain, Cigno and Ermisch (1989) found a negative effect of work experience on birth rates. However, they only measured work experience before marriage and did not differentiate by birth order. Occupation was found to have an effect on fertility timing in Great Britain and the United States. The effect of time in the labor market on first birth risks was found to differ by level of educational attainment in the Czech Republic after 1989 and in West Germany. 


\section{Data and methods}

The data used for this study is from the British Household Panel Survey ${ }^{2}$ (BHPS). In the BHPS, respondents are surveyed once a year. The BHPS began in 1991. At each panel wave of the BHPS, respondents are asked for their activity histories for the past year. The starting and ending months of main activities (such as employment, education, unemployment, or family care) across the preceding year are recorded without gaps. It is also possible to reconstruct birth and education histories across the panel years of the BHPS. In addition, in the $2^{\text {nd }}$ wave in 1992, complete retrospective fertility, partnership, and employment status histories were collected. For the following analysis, retrospective parts of the BHPS were combined with panel data of the waves 1991-2001. This made it possible to analyze complete fertility, employment, and education histories, pertaining to the years 1961 to 2001.

The sample consists of women born in Great Britain between 1940 and 1984. Only members of the initial BHPS sample were included, and not members of any of the extension samples that joined the BHPS later between waves 7 and 11. This leaves a sample size of 3273. During the period of analysis, 2063 first children were born.

The statistical program that was used is aML. The general formula for the models estimated is given below.

$$
\ln \mathrm{h}_{\mathrm{i}}(\mathrm{t})=\mathrm{y}(\mathrm{t})+\sum_{k=1}^{l} \alpha_{k} x_{i k}+\sum_{k=1}^{m} \beta_{k} w_{i k}(t)+\sum_{k=1}^{n} z_{k}\left(t-v_{i k}\right)
$$

The $\log$ risk of first conception is $\ln h_{i}(t)$. The baseline duration used is age $(t)$, measured in time since the respondent turned 16. Accordingly, $y(t)$ is the log baseline risk of first conception, modeled as a piece-wise linear spline. Only one time-constant variable, cohort membership, is included. A set of dummy variables for cohort membership is given by the $x_{i k}$, and the $\alpha_{\mathrm{k}}$ are the coefficients for the effect of cohort

\footnotetext{
${ }^{2}$ The BHPS data used in this study were made available through the ESRC Data Archive. The data were originally collected by the ESRC Research Centre on Micro-social Change at the University of Essex (now incorporated in the Institute for Social and Economic Research). Neither the original collectors of the data nor the Archive bear any responsibility for the analyses or interpretations presented here.
} 
membership on the log risk of first birth. Time-varying variables in the models are given by the $w_{i k}(t)$. These are employment status, previous employment experience, union order, and educational attainment. Further duration splines are union duration, marriage duration, and present full-time employment duration. The duration since the beginning of each process is given by $\left(t-v_{i k}\right)$, where the $v_{i k}$ represent the length of the interval between the time the respondent turned 16 and the beginning of the given process. The splines giving the effects of duration in each given state on the log risk of first birth are the $\mathrm{z}_{\mathrm{k}}\left(t-v_{i k}\right)$.

In the following, the expression 'first birth risks' is sometimes used for simplicity, although first birth was backdated by 9 months. Thus, the object of study is always the risk of first conception, even if the expression 'first birth risks' is sometimes used.

\section{Empirical results}

As outlined earlier, the main hypotheses tested in this section are that work experience has a positive effect on first birth risks for all women, and that this effect is stronger for women with higher levels of education. The models presented in the following distinguish between effects of current work experience and previous work experience on first birth risks. Current work experience is defined as all of the work experience that has been accumulated during the present employment spell. Previous work experience is all the work experience that has been accumulated prior to the present employment spell, in other words, work experience that is separated from the current spell by an employment break. Current work experience is not necessarily identical to tenure. Current work experience, defined as an uninterrupted employment spell, can have been entirely acquired working for the same employer. It can however also have been acquired working for several different employers sequentially, if transitions from one employer to the other were made smoothly, without any intermittent phases of non-employment. In this case, it is likely that the employer changes were voluntary, and that skills acquired in sequential jobs build on each other. The idea is that previous work experience separated by a phase of non-employment should be less important for fertility decision-making than current work experience. If there are breaks separating employment episodes, human capital previously accumulated is likely to 
have depreciated. Then, basic skills need to be reacquired in the initial phases of the new job.

In this study, effects of full-time work experience only on first birth risks are studied. Career development is likely to be very different in part-time than in full-time jobs. Models testing for the effect of part-time work experience on first birth risks have also been run. The effect of part-time work experience on first birth risks was found to be largely negative. However, case numbers are quite small, thus preventing stable results. Therefore, this study concentrates on full-time work experience only.

Table 1 shows a model testing for the effect of full-time work experience on first birth risks. The estimates for the effect of work experience are plotted in figure 4 (curve labeled 'controlling for union duration'). An especially strong positive effect of continuous full-time employment experience is found across the first year of employment. After one year of continuous full-time employment, first birth risks are about $70 \%{ }^{3}$ higher than at the beginning of the employment spell. After the first year of employment, work experience continues to have a positive effect, but the effect is now weaker. Across the next 3 years, first birth risks rise by only $7 \%(\exp (0.002 * 36) \approx$ 1.07). Between 4 and 8 years of work experience, first birth risks rise by another $27 \%$. After 8 years of work experience, there is practically no further increase in first birth risks. Previous full-time work experience, by contrast, has no effect on first birth risks. These results support the hypothesis of a positive general effect of continuous work experience on first birth risks. Women working full-time appear to postpone first birth until they have gained some experience within their current employment spell. The reason may be that they want to lengthen the period of employment before an interruption to maximize life-time earnings, as predicted by economic models of fertility timing. It could also be the case that they want to move on in their jobs and secure a good position before having a first child. However, the greatest increase in first birth risks is across the first year of the employment spell. This seems to indicate that beginning a new employment spell leads to a short-time postponement of the decision to have a first child. No hypothesis was formulated specifically concerning short-term developments, but this pattern is quite plausible. When starting a new job, people will want to find out more about the working conditions specific to the job be-

\footnotetext{
${ }^{3}$ Table 1 gives the effect of employment experience on first birth risks in log monthly factors of increment. Thus, first birth risks rise across the first year of employment experience by a factor of $\exp (0.044 * 12) \approx 1.70$.
} 
fore making a decision with such long-term consequences as having a first child. That there is no significant effect of previous work experience in this model also supports the hypothesis that current work experience is more important for first birth decisions than previous work experience. 
Table 1: Risk of first birth.

Model including union and marriage duration

Estimates are log relative risks

\begin{tabular}{|c|c|c|}
\hline \multirow{2}{*}{\multicolumn{3}{|c|}{$\begin{array}{l}\text { age } \\
\text { slopes (increment per month) }\end{array}$}} \\
\hline & & \\
\hline $16-18$ & 0.026 & $* \star *$ \\
\hline $18-22$ & -0.015 & $* * *$ \\
\hline $22-30$ & 0.000 & \\
\hline $30-45$ & -0.011 & $* * *$ \\
\hline \multicolumn{3}{|l|}{ union duration } \\
\hline intercept & 1.031 & $* * *$ \\
\hline \multicolumn{3}{|l|}{ slopes (increment per month) } \\
\hline $0-2$ years & 0.013 & ** \\
\hline 2-6 years & -0.007 & * \\
\hline $6+$ years & 0.003 & \\
\hline \multicolumn{3}{|l|}{ marriage duration } \\
\hline intercept & 1.051 & $* * *$ \\
\hline \multicolumn{3}{|l|}{ slopes (increment per month) } \\
\hline $0-2$ years & -0.003 & \\
\hline 2-6 years & 0.000 & \\
\hline $6+$ years & -0.018 & *** \\
\hline \multicolumn{3}{|l|}{$\begin{array}{l}\text { full-time employment duration } \\
\text { slopes (increment per month) }\end{array}$} \\
\hline $0-1$ year & 0.044 & $* \star *$ \\
\hline $1-4$ years & 0.002 & \\
\hline $4-8$ years & 0.005 & ** \\
\hline $8+$ years & 0.000 & \\
\hline \multicolumn{3}{|c|}{$\begin{array}{l}\text { employment status (reference category: beginning of } \\
\text { full-time employment) }\end{array}$} \\
\hline part-time employed & 0.811 & $* * *$ \\
\hline self-employed & 0.389 & * \\
\hline not employed & 1.465 & $* * *$ \\
\hline other empl. status & 0.183 & \\
\hline in education & -0.572 & *** \\
\hline previous full-time experience (months) & 0.000 & \\
\hline \multicolumn{3}{|l|}{ union order } \\
\hline 1st union & 0 & \\
\hline 2nd union & 0.000 & \\
\hline $3 r d+$ union & 0.367 & ** \\
\hline \multicolumn{3}{|l|}{ cohort } \\
\hline $1940-1949$ & 0 & \\
\hline 1950-1959 & -0.069 & \\
\hline $1960-1969$ & 0.016 & \\
\hline 1970-1984 & -0.023 & \\
\hline \multicolumn{3}{|l|}{ educational attainment (school degree) } \\
\hline no degree & 0.369 & $* * *$ \\
\hline low & 0.251 & $* * *$ \\
\hline medium & 0 & \\
\hline high & -0.176 & $* *$ \\
\hline
\end{tabular}




\section{Figure 4}

Effect of employment status and full-time employment duration on first birth risks in models including and not including partnership status and union duration

Risks relative to the beginning of full-time employment

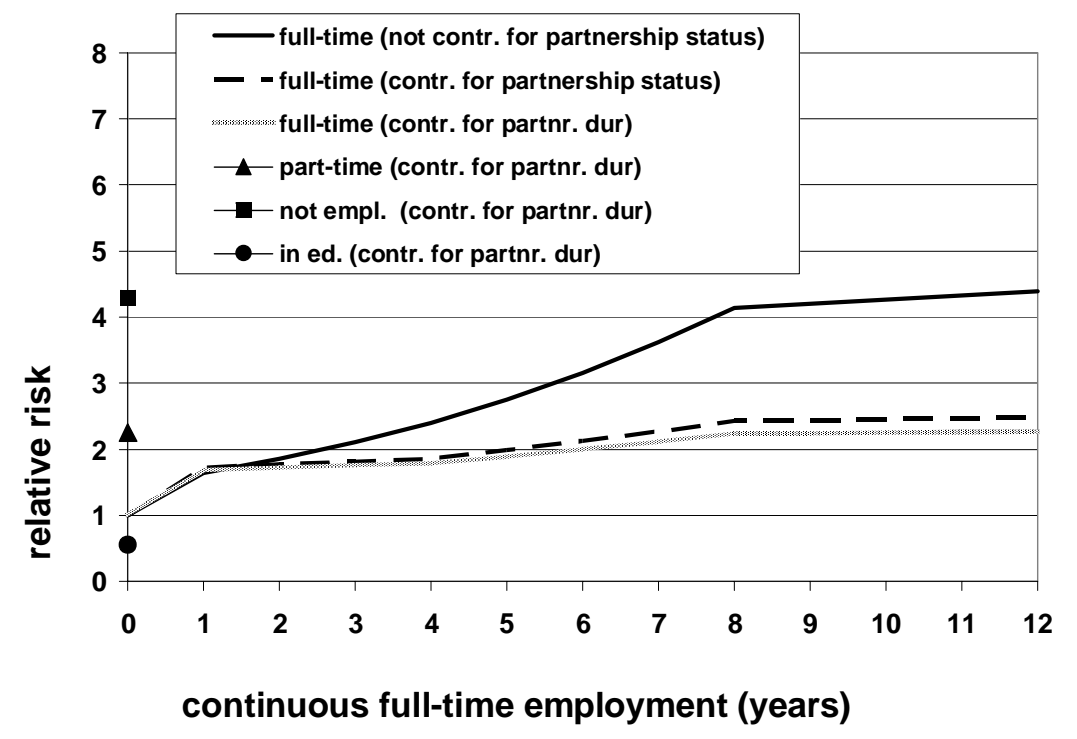

The model shown in table 1 also controls for partnership status and duration. As one can see in figure 4, estimates for the effect employment experience depend on whether partnership status and duration are controlled for or not. The effect of work experience is estimated to be quite a lot stronger in the model not controlling for partnership status. The difference in effects of work experience between the different models is especially large between 1 and 8 years of employment experience. In all models however, the effect of continuous employment duration is found to be positive. There is especially little difference in the size of the effect estimated for the first year of an employment spell.

Whether to include controls for union and marriage duration when studying the effect of work experience is however debatable. On the one hand, work experience could be correlated with union duration. Estimates for the effects of work experience on first birth risks may therefore just be picking up effects of union duration if it is not controlled for. On the other hand, union duration should be more strongly correlated with age than with work experience, and age is controlled for in any case. More importantly though, causality may be in the opposite direction. The decisions to get married and to have children will often be simultaneous decisions. If people have gathered some work experience and feel that other factors as well are right, they decide to 
get married and also subsequently to have children. Thus, cohabitation, and more so marriage, could just be an indicator that the decision to start the process of family formation has already been made.

To test the hypothesis that employment duration has a stronger positive effect on first birth risks for women with high levels of education than for those with lower levels of education, a model interacting education with employment duration was run (table 2). The model for which the estimates are shown in table 2 does not include partnership status or union duration. However, in figure 5 below, the effects of continuous work experience by education in this model can be compared to the effects in a model controlling for union and marriage duration, shown in figure 6.

Figure 5 shows positive effects of continuous work experience for all educational groups, except for women with low education between 1 and 4 years of work experience and women with high education after 8 years of work experience. There is no clear indication of a stronger effect of work experience for women with higher levels of education. Instead, the effect of work experience on first birth risks seems to be relatively similar for all educational groups. In the model controlling for marriage and union duration, shown in figure 6, long-term effects of work experience on first birth risks are weakened for all educational groups. The increase in first birth risks across the first year of employment remains stable however. For most educational groups, there is no longer any uniform direction for the development of first birth risks after one year of continuous work experience.

In both models, the peak in first birth risks for women with a high level of education seems to be at 8 years of employment duration. Women with high education postpone first birth across the first 4 years of employment duration, whereafter the risk of first birth rises to its highest level at 8 years of employment. The most straightforward positive effect of employment experience on first birth risks was found for women with a medium level of education. Women with low education seem to postpone first births until after 8 years of continuous employment. Like women with high education, those with no education postpone first births until after 4 years of employment experience. So, there seems to be some pattern of postponement of first birth immediately after starting employment, and then again until after 4 years of employment experience. First birth risks tend to be higher after 4 years, and sometimes after 8 years of employment experience than before. It is difficult, though, to come to 
any clear conclusion for which educational group the effect of employment experience on first birth risks is greatest.

In the models interacting education and employment experience, the interaction between education and age is also controlled for. As one can see in table 2, the shape of the effect of age on first birth risks varies strongly between educational groups. This is likely to be due to differences in age at completion of education and differences in age norms of childbearing. If this interaction between age and education had not been controlled for in the model shown in table 2, the interaction between employment experience and education would have been distorted. The aim here was specifically to gain a picture of differences in the effect of employment experience by level of education, net of differences caused by diverging age norms or time-squeeze effects for women with higher levels of education.

In table 2 , one can also see that the effect of previous work experience is now significant and positive. This is the case in all models not controlling for partnership status. Previous work experience seems to be correlated with the likelihood of being in a partnership. In this model then, there is not as much support for the hypothesis that previous work experience is less important for decisions to have a first child. The effect of previous work experience is however less stable than the effect of current work experience, since it no longer holds when controlling for partnership status. 
Table 2

Risk of first birth: interaction of education with full-time employment duration and age (model not controlling for partnership status or union duration)

\section{Estimates are log relative risks}

\section{constant}

$-5.945 * * *$

interaction of age and education

age (no degree)

slopes (increment per month)

16-20

20-25

25-32

$32-45$

age (low education)

intercept

slopes (increment per month)

16-20

20-25

25-30

30-45

age (medium education)

intercept

slopes (increment per month)

16-20

20-25

25-32

$32-45$

age (high education)

intercept

slopes (increment per month)

16-20

20-25

25-30

30-36

36-45

0.022

$-0.011$

$-0.015$

$-0.026 * * *$

$-0.692$

0.024

0.000

-0.016 **

$-0.038 * * *$

$-0.326$

0.010

0.003

$-0.009$

$-0.029$

$-0.955$

0.002

0.008

0.003

$-0.012$

$-0.024$

interaction of full-time employment duration and education

full-time employment duration (no degree)

slopes (increment per month)

$0-1$ year

0.029

1-4 years

0.002

4-8 years

0.016

$8+$ years

0.008

full-time employment duration (low education)

intercept

$-0.006$

slopes (increment per month)

0-1 year

$1-4$ years

$-0.008$

4-8 years

0.011

$8+$ years

0.018 
full-time employment duration (medium education)

intercept

slopes (increment per month)

0 -1 year

0.036

1-4 years

0.014

4-8 years

$0.011 * * *$

$8+$ years

0.006

full-time employment duration

(high education)

intercept

0.226

slopes (increment per month)

0-1 year

0.068

1-4 years

0.004

4-8 years

$0.015 * * *$

$8+$ years

$-0.007$

\section{employment status}

(reference category: beginning of full-time employment (no degree)

part-time employed

$1.083^{* * *}$

self-employed

0.649

1.805

not employed

0.126

other empl. status

$-0.937$

in education

0.007

(months)

cohort

1940-1949

0

1950-1959

$-0.033$

1960-1969

$-0.083$

1970-1984

$-0.342 * * *$

${ }^{* * *}: p<0.01 ;{ }^{* *}: 0.01 \leq p<0.05 ;{ }^{*}: 0.05 \leq p<0.1$ 
Figure 5

Effect of full-time employment duration on first birth risks by education (model not controlling for partnership status or union duration)

Risks relative to the beginning of each spline

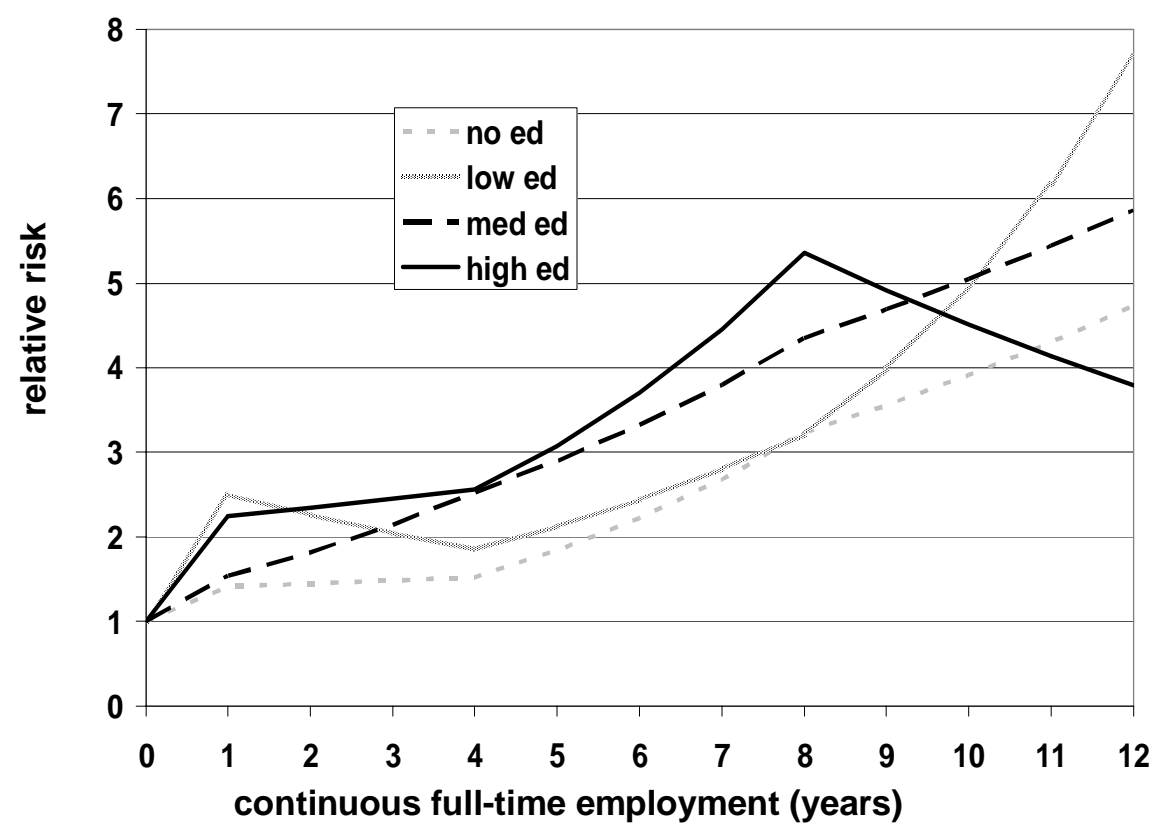

Figure 6

Effect of full-time employment duration on first birth risks by education (model controlling for partnership status and union duration)

Risks relative to the beginning of each spline

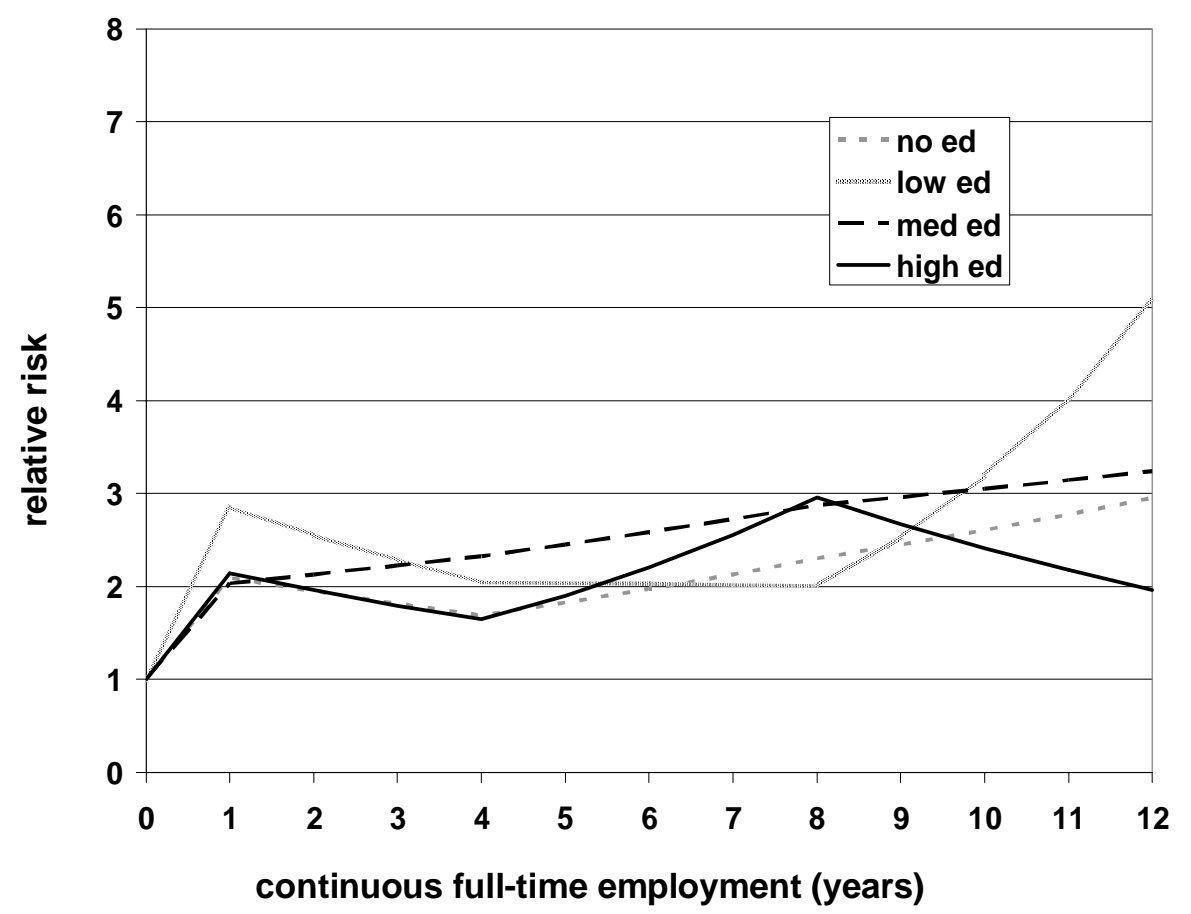




\section{Summary}

This paper examined the effect of work experience on transitions to first birth in Great Britain. According to economic theories of fertility timing, later birth timing within the employment career leads to higher life-time earnings. Therefore, a main hypothesis was that employment experience has a positive effect on first birth risks. Assuming that women with higher levels of qualification take more time to establish their careers, first birth timing should be more important for them. A second hypothesis was thus that work experience has a stronger effect on first birth risks for women with higher than for those with lower levels of education.

In the empirical analyses, employment experience was found to have a positive effect on first birth risks. This corresponds to the hypothesis that women postpone the decision to have a first child until they have acquired some work experience in order to maximize life-time earnings or to secure a good position before beginning family formation. However, there was not much support for the hypothesis that the effect of work experience is stronger for women with a high level of education.

A further finding was that first births are consistently postponed at the very beginning of a new employment spell. The steepest increase in first birth risks was found across the first year of a new employment spell. No hypothesis had been formulated in this direction. Nonetheless, this type of a pattern is quite plausible since people will want to find out more about the employment conditions in their new job before making the important and long-term decision to have a first child.

The size of the increase in first birth risks with employment experience beyond the first year of employment depended on whether partnership status was controlled for or not. In models not controlling for partnership status, the increase in first birth risks beyond the first year of employment was quite strong. In models controlling for partnership status, a positive effect of employment experience beyond the first year remained, but it was weaker. Since starting a cohabiting union or especially a marriage might just be an indicator that the decision to have child has already been made, it is however an ambivalent question whether to include partnership status. This is particularly the case since the simultaneous decision to marry and to have a first child may have been made in response to economic factors such as the length of employment experience. 
In all of the models, previous employment experience was distinguished from experience within the present employment spell. The idea was that one may not be able to profit from employment experience in the same way if it is separated from the present employment spell through employment interruptions. The hypothesis that current employment experience is more important than previous employment experience was partially supported. In models controlling for partnership status, there was no significant effect of previous employment experience, while the effect of current employment experience was significant. By contrast, in models that did not control for partnership status, there was a significant effect of previous employment experience in addition to the effect of experience within the current employment spell.

\section{Acknowledgements}

I would like to thank Michaela Kreyenfeld, Gerda Neyer, Gunnar Andersson, Karin Böttcher, Martin Spielauer, and Sutay Yavuz for valuable comments and advice. 


\section{References}

Andersson, Gunnar. 2000. The Impact of Labour-Force Participation on Childbearing Behaviour: Pro-Cyclical Fertility in Sweden During the 1980s and the 1990s. European Journal of Population 16: 293-333.

Bender, Stefan, Annette Kohlmann, and Stefan Lang. 2003. "Women, Work, and Motherhood: Changing Employment Penalties for Motherhood in West Germany After 1945 - A Comparative Analysis of Cohorts Born in 1934-1971." MPIDR Working Paper WP (006).

Blackburn, McKinley L., David E. Bloom, and David Neumark. 1993. Fertility Timing, Wages, and Human Capital. Journal of Population Economics 6: 1-30.

Blossfeld, Hans-Peter, and Johannes Huinink. 1991. Human Capital Investments or Norms of Role Transitions? How Women's Schooling and Career Affect the Process of Family Formation. American Journal of Sociology 97, no. 1: 143-68.

Brewster, Karin L. and Ronald R. Rindfuss. 2000. "Fertility and Women's Employment in Industrialized Nations." Annual Review of Sociology 26: 271-96.

British Household Panel Survey. 2001. computer file. Principle Investigator ESRC Research Centre on Micro-Social Change, Colchester. The Data Archive (Distributor), Data Files and Associated Documentation .

Cain, Glen G., and Adriana Weininger. 1973. Economic Determinants of Fertility: Results from Cross-Sectional Aggregate Data. Demography 10, no. 2: 205-23.

Cigno, Alessandro, and John Ermisch. 1989. A Microeconomic Analysis of the Timing of Births. European Economic Review 33: 737-60.

Department for Education and Skills. 2001. Statistics of Education: Children's Day Care Facilities at 31 March 2001 England. National Statistics Bulletin 8, no. 1.

Ermisch, John F. 1989. Purchased Child Care, Optimal Family Size and Mother's Employment. Journal of Population Economics 2: 79-102.

Evers, Adalbert, Jane Lewis, and Birgit Riedel. 2005. Developing child-care provision 
in England and Germany: problems of governance. Journal of European Social Policy 15, no. 3: 195-209.

Gustafsson, Siv S. 2001. Optimal Age at Motherhood. Theoretical and Empirical Considerations on Postponement of Maternity in Europe. Journal of Population Economics 14: 225-47.

Gustafsson, Siv S., Cécile M. M. P. Wetzels, Jan Dirk Vlasblom, and Shirley Dex. 1996. Women's Labor Force Transitions in Connection with Childbirth: A Panel Data Comparison Between Germany, Sweden and Great Britain. Journal of Population Economics 9: 223-46.

Happel, S. K., J. K. Hill, and S. A. Low. 1984. An Economic Analysis of the Timing of Childbirth. Population Studies 38, no. 2: 299-311.

Hotz, V. Joseph, Jacob Alex Klerman, and Robert J. Willis. 1997. The Economics of Fertility in Developed Countries. Handbook of Population and Family Economics. Volume 1A. Mark R. Rosenzweig, and Oded Stark, 275-347. Amsterdam.

Joshi, Heather. 1990. The Cash Opportunity Costs of Childbearing: An Approach to Estimation using British Data. Population Studies 44, no. 1: 41-60.

Joshi, Heather. 2002. "Producation, Reproduction, and Education: Women, Children, and Work in a British Perspective." Population and Development Review 28(3):445-74.

Kantorová, Vladimíra. 2004. Education and Entry into Motherhood: The Czech Republic during State Socialism and the Transition Period (1970-1997). Demographic Research Special Collection 3: 243-74.

Kravdal, Oystein. 1994. The Importance of Economic Activity, Economic Potential and Economic Resources for the Timing of First Births in Norway. Population Studies 48: 249-67.

Kreyenfeld, Michaela. 2004. Fertility Decisions in the FRG and GDR: An Analysis with Data from the German Fertility and Family Survey. Demographic Research Special Collection 3: 273-318. 
Kreyenfeld, Michaela. 2005. Economic Uncertainty and Fertility Postponement. Evidence from German Panel Data. Beitrag Für Die Ausschussitzung Des Vereins Für Socialpolitik.

Lappegård, Trude and Marit Rønsen. 2005. "The Multifaceted Impact of Education on Entry into Motherhood." European Journal of Population 2131-49.

Leibenstein, Harvey. 1957. Population Growth Theory and Economic Development. Economic Backwardness and Economic Growth. Harvey Leibenstein, 147-75. New York; London.

Lillard, Lee A. and Constantijn W. A. Panis. 2003. aML Multilevel Multiprocess Statistical Software, Version 2.0. Los Angeles, California: EconWare.

Mincer, Jacob. 1963. Market Prices, Opportunity Costs, and Income Effects. Measurement in Economics: Studies in Mathematical Economics and Econometrics in Memory of Yehuda Grunfeld. C. F. et al. Christ, 67-82. Stanford.

Randall, Vicky. 1996. The Politics of Childcare Policy. Parliamentary Affairs 49, no. 1: $176-90$.

Ranson, Gillian. 1998. Educaton, Work and Family Decision Making: Finding the "Right Time" to Have a Baby. CRSA/RCSA.

Schultz, T. Paul. 1969. An Economic Model of Family Planning and Fertility. 77, no. 2: $153-80$.

Taniguchi, Hiromi. 1999. The Timing of Childbearing and Women's Wages. Journal of Marriage and the Family 61: 1008-19.

Ward, Clare, Angela Dale, and Heather Joshi. 1996. Combining Employment with Childcare: An Escape from Dependence? Journal of Social Policy 25, no. 2: 22347.

Woodland, Stephen, Melisa Miller, and Sarah Tipping. 2004. Repeat Study of Parent's Demand for Childcare. National Centre for Social Research. Department for Education and Skills. Research Report No. 348. 
Vikat, Andres. 2004. Women's Labor Force Attachment and Childbearing in Finland. Demographic Research Special Collection 3: 175-212. 


\section{Appendix}

Figure A3.1 illustrates a model of linear wage appreciation and depreciation. The first segment of the wage function is given by $f_{1}$, which would also represent the development of wages over the whole time period if there were no interruption. The function for wage depreciation during absence from the labor market is $f_{2}$. Finally, wage development in the period after labor market reentry is given by $f_{3}$, for which the same gradient is assumed as for $\mathrm{f}_{1}$.

Figure A1: wages do not completely depreciate

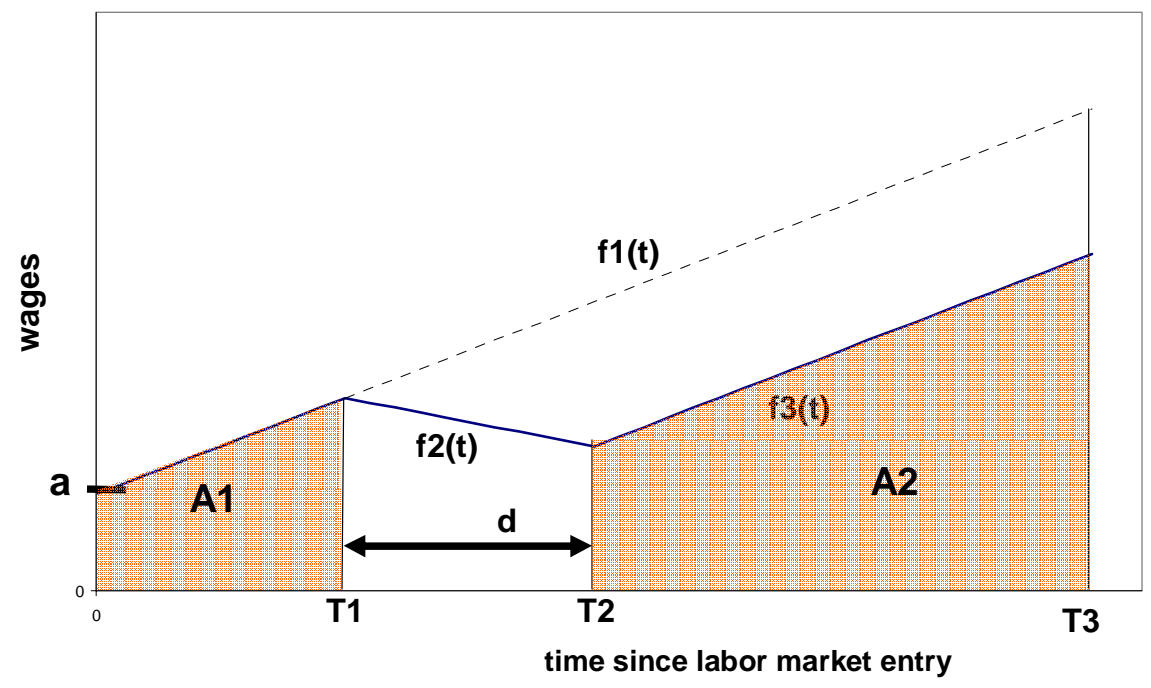

The functions are defined as below:

$f_{1}(t)=a+b_{1} t$

$f_{2}(t)=u+b_{2} t=a-T_{1} *\left(b_{2}-b_{1}\right)+b_{2} t$

$f_{3}(t)=v+b_{1} t=a+\left(b_{2}-b_{1}\right) *\left(T_{2}-T_{1}\right)+b_{1} t$

Life-time earnings, $E$, are given by the sum of the areas $A_{1}$ and $A_{2}$.

$A_{1}=\int_{0}^{T_{1}} f_{1}(t) d t=a T_{1}+\frac{1}{2} b_{1} T_{1}^{2}$ 
$A_{2}=\int_{T_{2}}^{T_{3}} f_{3}(t) d t=\left(a+\left(b_{2}-b_{1}\right)\left(T_{2}-T_{1}\right)\right) *\left(T_{3}-T_{2}\right)+\frac{1}{2} b_{1} *\left(T_{3}^{2}-T_{2}^{2}\right)$

$E=A_{1}+A_{2}=-a\left(T_{2}-T_{1}\right)+\frac{1}{2} b_{1} T_{1}^{2}-\frac{1}{2} b_{1} T_{2}^{2}+\left(b_{2}-b_{1}\right) T_{3}\left(T_{2}-T_{1}\right)$

$-\left(b_{2}-b_{1}\right) T_{2}^{2}+\left(b_{2}-b_{1}\right) T_{1} T_{2}+\frac{1}{2} b_{1} T_{3}^{2}+a T_{3}$

defining: $d=T_{2}-T_{1}$

$T_{2}-T_{1}$ is replaced by $d$, for the duration of absence from the labor market. In this manner, one can see what effect timing, represented by $T_{2}$, has when the duration, $d$, is held constant.

Life-time earnings:

$$
E=-b_{2} d T_{2}+\frac{1}{2} b_{1} d^{2}-a * d+\left(b_{2}-b_{1}\right) T_{3} * d+\frac{1}{2} b_{1} T_{3}^{2}+a T_{3}
$$

The effect of birth timing on life-time earnings:

$$
\frac{\partial E}{\partial T_{2}}=-b_{2} d
$$

Thus, the effect of $T_{2}$ on life-time earnings is positive (since the wage gradient during absence $\left(b_{2}\right)$ is always negative). In other words, later birth timing leads to higher lifetime earnings. The positive effect of birth timing on life-time earnings is stronger for longer durations of absence from the labor market as well as higher rates of wage depreciation during absence. One can also see here that there is zero effect of birth timing on life-timing earnings if either the rate of wage depreciation during absence or the length of absence from the labor market is zero. 
Figure A2: wages depreciate completely during absence

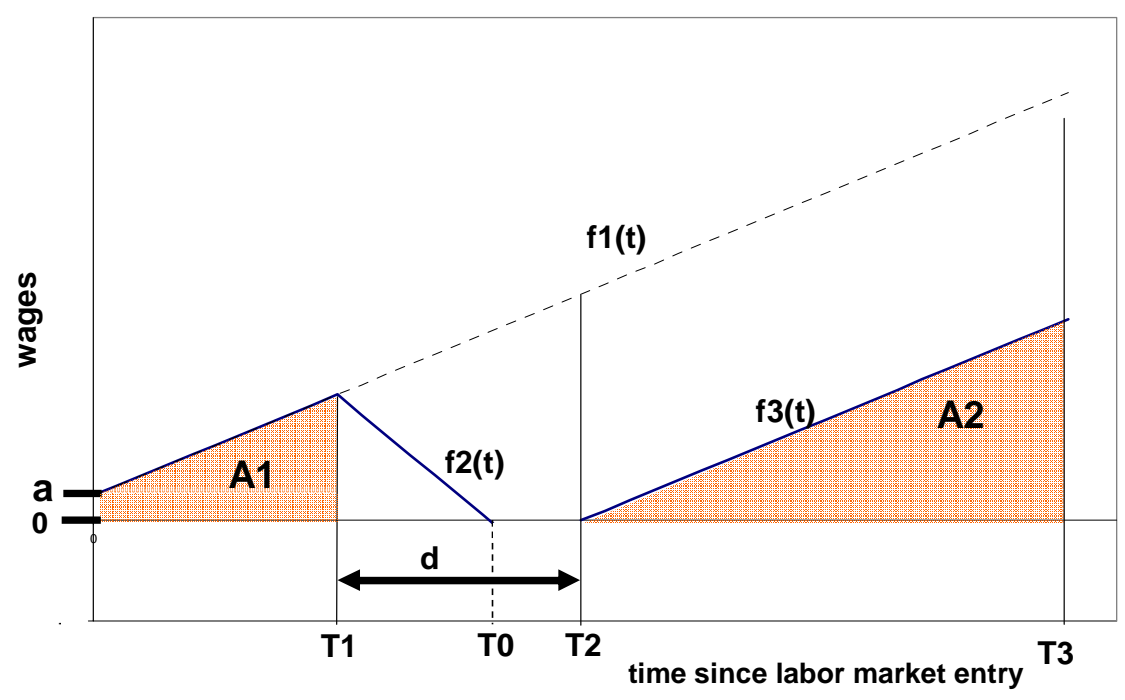

$T_{0}=\frac{-a+T_{1} *\left(b_{2}-b_{1}\right)}{b_{2}}$

The second scenario applies whenever $T_{0}$ is smaller than $T_{2}$.

$T_{0}<T_{2}$

$\Leftrightarrow \quad T_{2}<\frac{-d^{*}\left(b_{2}-b_{1}\right)-a}{b_{1}}$

( $b_{2}$ is always negative; $d=T_{2}-T_{1}$ )

When wages depreciate completely during absence from the labor market, that is, as soon as $\mathrm{T}_{2}$ is smaller than the value given above, the second scenario applies and a different formula for life-time earnings is needed.

The functions $f_{1}(t)$ and $f_{2}(t)$ are still the same as in the first scenario, but the function $f_{3}(t)$ is different:

$f_{3}(t)=-b_{1} T_{2}+b_{1} t$ 
The formula for $\mathrm{A}_{2}$ changes accordingly:

$$
\begin{aligned}
& A_{2}=\int_{T_{2}}^{T_{3}} f_{3}(t) d t=-b_{1} T_{2} *\left(T_{3}-T_{2}\right)+\frac{1}{2} b_{1} *\left(T_{3}^{2}-T_{2}^{2}\right) \\
& E=A_{1}+A_{2}=T_{2}\left(a+b_{1}\left(T_{2}-T_{3}-d\right)\right)-a d+\frac{1}{2} b_{1} d^{2}+\frac{1}{2} b_{1} T_{3}^{2} \\
& \frac{\partial E}{\partial T_{2}}=2 b_{1} T_{2}+a-b_{1}\left(T_{3}+d\right)
\end{aligned}
$$

To get the overall effect of first birth timing on life-time earnings, one needs to combine the results for the first scenario with the results for the second scenario. One switches from one function of $T_{2}$ to the other in dependence of the value of $T_{2}$ itself. As shown earlier, the second scenario applies as long as:

$T_{2}<\frac{-d *\left(b_{2}-b_{1}\right)-a}{b_{1}}$

While this is the case, the effect of birth timing on life-time earnings is:

$$
\frac{\partial E}{\partial T_{2}}=2 b_{1} T_{2}+a-b_{1}\left(T_{3}+d\right)
$$

As soon as $\mathrm{T}_{2}$ is larger than the threshold

$$
T_{2} \geq \frac{-d *\left(b_{2}-b_{1}\right)-a}{b_{1}}
$$

the first scenario applies, and the effect of timing $\left(\mathrm{T}_{2}\right)$ on life-time earnings is given by the following :

$$
\frac{\partial E}{\partial T_{2}}=-b_{2} d
$$


Figure A3: skill appreciation slows with time

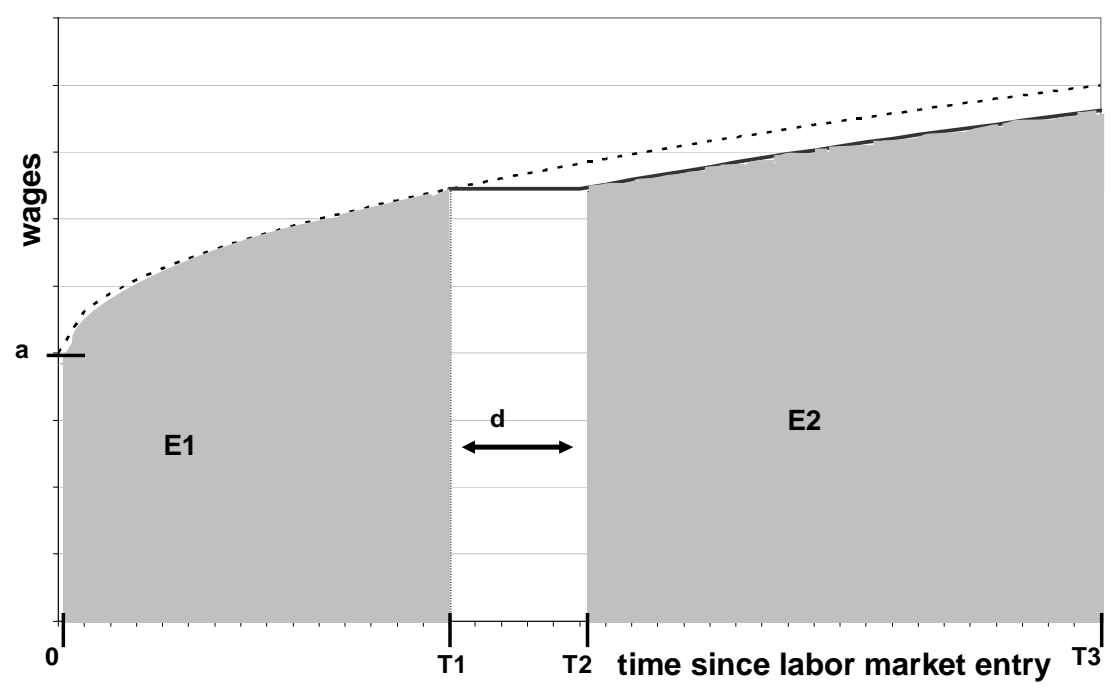

The wage function before the break

$w_{1}(t)=a+b * t^{c}$

where $0<c<1$

The wage function after the break

$w_{2}(t)=w_{1}(t)-\left(w_{1}\left(T_{2}\right)-w_{1}\left(T_{1}\right)\right)$

$=a+b *\left(\left(T_{2}-d\right)^{c}-T_{2}^{c}\right)+b * t^{c}$

Life-time earnings as the area under the curve

$$
\begin{aligned}
& E=E_{1}+E_{2}=\int_{0}^{T_{1}} w_{1}(t) d t+\int_{T_{2}}^{T_{3}} w_{2}(t) d t \\
& =\frac{b}{c+1} *\left(T_{2}-d\right)^{c+1}-\frac{b}{c+1} * T_{2}^{c+1}+b T_{3}\left(T_{2}-d\right)^{c} \\
& -b T_{2}\left(T_{2}-d\right)^{c}-b T_{3} T_{2}{ }^{c}+b T_{2}{ }^{c+1}+a\left(T_{3}-d\right)+\frac{b}{c+1} * T_{3}^{c+1}
\end{aligned}
$$

The effect of timing of employment interruption on life-time earnings:

$$
\frac{\partial E}{\partial T_{2}}=c b\left(T_{3}-T_{2}\right)\left(\left(T_{2}-d\right)^{c-1}-T_{2}^{c-1}\right)
$$


The effect of later birth timing on life-time earnings is positive:

$\operatorname{cb}\left(\mathrm{T}_{3}-\mathrm{T}_{2}\right)>0$

$\left(T_{2}-d\right)^{c-1}-T_{2}^{c-1}>0$ (c is smaller than 1$)$

The longer the break $(d)$, the more important is timing for life-time earnings. 